\title{
Charcot-Marie-Tooth type 4B2 demyelinating neuropathy in miniature Schnauzer dogs caused by a novel splicing SBF2 (MTMR13) genetic variant: a new spontaneous clinical model
}

\author{
Nicolas Granger ${ }^{\text {Corresp., } 1,2}$, Alejandro Luján Feliu-Pascual ${ }^{3}$, Charlotte Spicer $^{4}$, Sally Ricketts ${ }^{5}$, Rebekkah Hitti ${ }^{5}$, \\ Oliver Forman ${ }^{5}$, Joshua Hersheson ${ }^{4}$, Henry Houlden ${ }^{4}$ \\ ${ }^{1}$ Royal Veterinary College, University of London, Hatfield, United Kingdom \\ 2 Bristol Veterinary Specialists, CVS Referrals, Bristol, United Kingdom \\ 3 Neurology / Neurosurgery Service, Aúna Especialidades Veterinarias, Valencia, Spain \\ 4 Department of Molecular Neuroscience, UCL Institute of Neurology \& National Hospital for Neurology and Neurosurgery \& London, London, United \\ Kingdom \\ ${ }^{5}$ Kennel Club Genetics Centre, Animal Health Trust, Newmarket, United Kingdom \\ Corresponding Author: Nicolas Granger \\ Email address: nicolasgranger@rvc.ac.uk
}

Background Charcot-Marie-Tooth (CMT) disease is the most common neuromuscular disorder in humans affecting 40 out of 100,000 individuals. In 2008, we described the clinical, electrophysiological and pathological findings of a demyelinating motor and sensory neuropathy in Miniature Schnauzer dogs, with a suspected autosomal recessive mode of inheritance based on pedigree analysis. The discovery of additional cases has followed this work and led to a genome-wide association mapping approach to search for the underlying genetic cause of the disease.

Methods For genome wide association screening, genomic DNA samples from affected and unaffected dogs were genotyped using the Illumina CanineHD SNP genotyping array. SBF2 and its variant were sequenced using primers and PCRs. RNA was extracted from muscle of an unaffected and an affected dog and RT-PCR performed. Immunohistochemistry for myelin basic protein was performed on peripheral nerve section specimens.

Results The genome-wide association study gave an indicative signal on canine chromosome 21. Although the signal was not of genome-wide significance due to the small number of cases, the SBF2 (also known as MTMR13) gene within the region of shared case homozygosity was a strong positional candidate, as 22 genetic variants in the gene have been associated with demyelinating forms of CharcotMarie-Tooth disease in humans. Sequencing of SBF2 in cases revealed a splice donor site genetic variant, resulting in cryptic splicing and predicted early termination of the protein based on RNA sequencing results.

Conclusions This study reports the first genetic variant in Miniature Schnauzer dogs responsible for the occurrence of a demyelinating peripheral neuropathy with abnormally folded myelin. This discovery establishes a genotype / phenotype correlation in affected Miniature Schnauzers that can be used for the diagnosis of these dogs. It further supports the dog as a natural model of a human disease; in this instance Charcot-Marie-Tooth disease. It opens avenues to search the biological mechanisms responsible for the disease and to test new therapies in a non-rodent large animal model. In particular, recent gene editing methods that led to the restoration of dystrophin expression in a canine model of muscular dystrophy could be applied to other canine models such as this before translation to humans.

PeerJ reviewing PDF | (2019:04:37233:1:1:NEW 26 Sep 2019) 
1 Charcot-Marie-Tooth type 4B2 demyelinating neuropathy in

2 miniature Schnauzer dogs caused by a novel splicing SBF2

3 (MTMR13) genetic variant: a new spontaneous clinical model

4

5

Nicolas Granger ${ }^{1,2}$, Alejandro Luján Feliu-Pascual ${ }^{3}$, Charlotte Spicer ${ }^{4}$, Sally L. Ricketts ${ }^{5}$,

Rebekkah J. Hitti ${ }^{5}$, Oliver P. Forman ${ }^{5}$, Joshua Hesheson ${ }^{4}$, Henry Houlden ${ }^{4}$ 10

11

1: The Royal Veterinary College, University of London, Hawkshead Lane, Hatfield, Hertfordshire,

2: CVS referrals, Bristol Veterinary Specialists at Highcroft, Bristol, United Kingdom.

3: Neurology / Neurosurgery Service, Aúna Especialidades Veterinarias, Algepser 22-1,

Paterna, Valencia, Spain.

4: Department of Molecular Neuroscience, UCL Institute of Neurology \& National Hospital for Neurology and Neurosurgery \& London, United Kingdom.

5: Kennel Club Genetics Centre, Animal Health Trust, Kentford, Newmarket, Suffolk, United Kingdom.

\section{Corresponding Author:}

Dr Nicolas Granger

The Royal Veterinary College, University of London, Hawkshead Lane, Hatfield, Hertfordshire, 31 United Kingdom \& CVS referrals, Bristol Veterinary Specialists at Highcroft, Bristol, United 32 Kingdom. 


\section{Abstract}

41

Background Charcot-Marie-Tooth (CMT) disease is the most common neuromuscular disorder in humans affecting 40 out of 100,000 individuals. In 2008, we described the clinical, electrophysiological and pathological findings of a demyelinating motor and sensory neuropathy in Miniature Schnauzer dogs, with a suspected autosomal recessive mode of inheritance based on pedigree analysis. The discovery of additional cases has followed this work and led to a genome-wide association mapping approach to search for the underlying genetic cause of the disease.

Methods For genome wide association screening, genomic DNA samples from affected and unaffected dogs were genotyped using the Illumina CanineHD SNP genotyping array. SBF2 and its variant were sequenced using primers and PCRs. RNA was extracted from muscle of an unaffected and an affected dog and RT-PCR performed. Immunohistochemistry for myelin basic protein was performed on peripheral nerve section specimens.

Results The genome-wide association study gave an indicative signal on canine chromosome 21. Although the signal was not of genome-wide significance due to the small number of cases, the SBF2 (also known as MTMR13) gene within the region of shared case homozygosity was a strong positional candidate, as 22 genetic variants in the gene have been associated with demyelinating forms of Charcot-Marie-Tooth disease in humans. Sequencing of SBF2 in cases revealed a splice donor site genetic variant, resulting in cryptic splicing and predicted early termination of the protein based on RNA sequencing results.

Conclusions This study reports the first genetic variant in Miniature Schnauzer dogs responsible for the occurrence of a demyelinating peripheral neuropathy with abnormally folded myelin. This discovery establishes a genotype / phenotype correlation in affected Miniature Schnauzers that can be used for the diagnosis of these dogs. It further supports the dog as a natural model of a human disease; in this instance Charcot-Marie-Tooth disease. It opens avenues to search the biological mechanisms responsible for the disease and to test new therapies in a non-rodent large animal model. In particular, recent gene editing methods that led to the restoration of dystrophin expression in a canine model of muscular dystrophy could be applied to other canine models such as this before translation to humans. 
74

75

76

77

78

79

80

81

82

83

84

85

86

87

88

89

90

91

92

93

94

95

96

97

98

99

100

101

102

103

104

105

106

\section{Introduction}

Charcot-Marie-Tooth (CMT) disease is the most common neuromuscular disorder of the human population, affecting 40 out of 100,000 individuals in Europe and the United States [1-3] and more than 2.6 million people worldwide [4]. It was jointly described by Drs. Charcot and Marie in Paris and Dr. Tooth in Cambridge in 1886 [5]. It is now well established that CMT disease refers to a wide group of degenerative motor and sensory neuropathies, $70 \%$ of which are hereditary $[2,6,7]$. More than 60 genes encompassing $\sim 900$ genetic variants have been implicated in the pathogenesis of CMT [8] offering the potential for further research to elucidate alterations in biological cascades causing the neuropathies. However, few advances have been made so far and CMT remains a slowly progressive and incurable disease. Current research is focused on the use of rodent transgenic models, which have several limitations. They are difficult and time consuming to obtain and the expected phenotype cannot be guaranteed [8], limitations that are not present with spontaneously occurring animal models.

In companion dogs, CMT-like diseases naturally occur, as evidenced by the phenotypic descriptions made by veterinarians in 22 breeds up until 2011 [, 10]. We have now entered a phase where veterinary researchers and canine geneticists are taking advantage of nextgeneration sequencing techniques in order to identify the molecular defects underlying these diseases in dogs, sometimes with a very small number of affected individuals [11, 12]. This promises to lead to an exponential unravelling of genetic variants in animals spontaneously affected by inherited neurological diseases.

In support of this, in the last decade, several variants within five different genes have been reported in eight canine breeds affected by inherited polyneuropathies similar to CMT disease in humans. First found in 2009, a deletion in the mitochondrial tRNATyr gene in Golden Retrievers causes a sensory neuropathy [13]. Following on, variants of the NDRG1 gene, implicated in myelination, cause an early-onset progressive polyneuropathy in Alaskan Malamutes [14] and a hereditary motor and sensory polyneuropathy in Greyhounds [15]. The ARHGEF10 gene, involved in neuronal growth and axonal migration, is mutated in some Leonberger and Saint Bernard dogs with severe juvenile-onset polyneuropathy and laryngeal paralysis [16] whereas a variant of the GJA9 gene, which is part of the connexin gap junction family proteins, causes a late onset polyneuropathy with laryngeal paralysis in Leonberger dogs [17]. Finally, the

Peer) reviewing PDF | (2019:04:37233:1:1:NEW 26 Sep 2019) 
107

108

109

110

111

112

113

114

115

116

117

118

119

120

121

122

123

124

125

126

127

128

129

130

131

132

133

134

135

136

137

138

139

140

RAB3GAP1 gene, involved in Rab proteins' function in membrane trafficking in the endoplasmic reticulum, axonal transport, autophagy and synaptic transmission, has a single nucleotide deletion in Black Russian terrier dogs [18] and a SINE insertion in Alaskan Huskies [19], leading to juvenile-onset, laryngeal paralysis, polyneuropathy and ocular changes similar to Warburg micro syndrome in humans. In Rottweilers, a variant in the same RAB3GAP1 gene causes neuronal vacuolation and spinocerebellar degeneration [20]. Older neuropathies, such as the well-known inherited sensory and autonomic in the Border Collie first described in 1987 [21], have also benefited from genetic advances. In 2016 one causal genetic variant of FAM134B, which encodes a cis-Golgi protein found in sensory and autonomic ganglion neurons, has been discovered [22] and two-years later, this mutation was also described in two mixed breed dogs [23]. In four other breeds, the German short-haired Pointer, the English Pointer, the English Springer Spaniel and the French Spaniel, some known since 1964, a similar inherited sensory and autonomic exist and found to be linked to a genetic variation of the long-non-coding RNA located upstream of the Glial cell-Derived Neurotrophic Factor gene, coding for a neurotrophic factor involved in neuronal development and adult neuronal survival [24]. The discovery of this genetic variant is particularly relevant to hereditary sensory and autonomic neuropathies in humans where it is not known.

In 2008, we described the clinical, electrophysiological and pathological findings of a demyelinating hereditary motor and sensory neuropathy in Miniature Schnauzer dogs, characterized by the presence of focally folded myelin sheaths also known as tomacula and segmental demyelination [25]. After exclusion of variants in the PMP22 and $P 0$ myelin genes by direct sequencing, the aim of this study was to demonstrate that the demyelinating hereditary motor and sensory neuropathy in Miniature Schnauzer dogs was genetic in origin by conducting a genome-wide association study (GWAS) and resequencing of candidate genes. From these investigations, a splice variant in the SBF2 (SET-binding factor 2), also known as MTMR13 (myotubularin-related protein-13) gene was identified. We will be using the official HUGO Gene Nomenclature Committee gene name SBF2 throughout the remainder of the manuscript to refer to the SBF2/MTMR13 gene.

\section{Materials \& Methods}

\section{Study samples}


141 All dogs were examined and investigated by veterinary neurologists. Blood was collected from

142 Miniature Schnauzers pre-mortem and tissue samples were collected post-mortem after dogs had

143 been euthanized on welfare grounds. Euthanasia was carried out solely to alleviate suffering and

144 no healthy individuals were sacrificed for use in this study. Euthanasia was carried out in

145 accordance with the Veterinary Surgeons Act 1966 and under the auspices of the RCVS. All

146 samples used in this study were collected after permission had been granted by dog owners (24-

147 2018E).

148

\section{Sample DNA and RNA extraction}

150 All DNA samples were collected from privately owned pet dogs by blood or tissue extraction using 151 the QIAamp midi or mini DNA extraction kit (Qiagen). Affected dogs are described below and some 152 have been previously reported. Controls were Miniature Schnauzer dogs that were reported as 153 clinically healthy with no sign of neuropathy based on our neurological examination of these cases $154(n=7)$, or apparently healthy Miniature Schnauzers with no owner report of neurological disorder $155(n=224)$. Cerebellum or muscle tissue samples were collected post-mortem and DNA and total 156 RNA extracted using the RNeasy midi kit (Qiagen). Genomic DNA from AHT control dogs utilized 157 for this study were derived from buccal swab samples or from residual blood drawn for diagnostic veterinary purposes as part of the dog's veterinary care. Samples were taken following informed and written owner consent. Sample collection for genetic research has been approved by the Animal Health Trust Ethics Committee (24-2018E).

Total RNA was extracted from homogenized muscle from an affected dog with two copies of the SBF2 variant and a control dog using a miRNeasy Mini Kit (Qiagen, Chatsworth, CA) according to the manufacturer's instructions. First-strand cDNA synthesis was then carried out using SuperScript II Reverse Transcriptase First-Strand Synthesis System for RT-PCR (Invitrogen / Life Technologies). The synthesizing conditions included initial 5 minutes' incubation at $65^{\circ} \mathrm{C}$ with dNTP and a mix of random hexamers/oligo dT primers, after which tubes were placed on ice for at least 1 minute. cDNA synthesis mix (5 x First-Strand Buffer, 0.1M DTT, RNase OUT) was added and incubated at $25^{\circ} \mathrm{C}$ for 2 minutes. SuperScript II was added and tubes incubated at $25^{\circ} \mathrm{C}$ for 10 minutes, followed by $42^{\circ} \mathrm{C}$ for 50 minutes. The reaction was terminated by incubation at $70^{\circ} \mathrm{C}$ for 5 171 minutes.

172

\section{GWAS analysis}


174 Genomic DNA samples from the first two Miniature Schnauzers diagnosed with a peripheral

175 neuropathy in France by one author (NG), and 39 Miniature Schnauzer controls were genotyped

176 using the Illumina CanineHD SNP genotyping array that comprises 173,662 SNPs (i.e. a total of

17741 dogs). The SNP genotyping dataset was analyzed for association using the statistical

178 package PLINK [26]. As part of the 41 dogs, a set of nine dogs (comprising the two affected

179 cases and seven controls) and a set of 32 controls were genotyped by two centers; University

180 College London ( $\mathrm{JH}, \mathrm{HH}$ ) and Animal Health Trust (SLR, RJH, OPF) respectively. To preserve

181 data quality SNP QC was conducted in each dataset independently before merging. Sample call

182 rates for all individuals were $>99 \%$. SNP quality control filtering excluded SNPs with a minor

183 allele frequency of less than $5 \%$ and a genotyping call rate of less than $97 \%$ in each

184 independent dataset. This resulted in 74,374 SNPs for association analysis in the merged

185 dataset. Multidimensional scaling analysis did not indicate the presence of population

186 stratification between the two sets (Supplementary file 1). Later, a further 192 Miniature

187 Schnauzers (Animal Health Trust) with no report of the disorder were included as a follow-up set

188 along with six other affected cases (five from Spain, one from Belgium), altogether leading to a

189 set of eight affected dogs and 231 controls.

190 Due to the very small sample size and disproportionate case-control ratio we conducted the

191 GWAS analysis using a Fisher's exact test with 100,000 permutations (max(T) permutation

192 procedure) to account for multiple testing. (The threshold for genome-wide statistical association

193 after permutation is 1.3.)

194

195 SBF2 resequencing

196 This was done using the two originally described French cases; five affected cases available from

197 Spain; and one case from Belgium - these dogs presented with similar neurological and

198 electrophysiological signs as originally described. Genomic DNA was amplified using a standard

199 touchdown PCR reaction. Cycling conditions were as follows: $94^{\circ} \mathrm{C}$ (5 minutes); $94^{\circ} \mathrm{C}(30$ seconds),

$20060^{\circ} \mathrm{C}$ (30 seconds), $72^{\circ} \mathrm{C}\left(45\right.$ seconds) for 25 cycles; $94^{\circ} \mathrm{C}$ (30 seconds) $50^{\circ} \mathrm{C}\left(30\right.$ seconds) $72^{\circ} \mathrm{C}$

201 (45 seconds) for $13 / 18$ cycles, $72^{\circ} \mathrm{C}$ (10 minutes). Primers for each of 35 coding exons with flanking

202 intronic regions were designed with PrimerZ (http://genepipe.ngc.sinica.edu.tw/primerz/) (see

203 sequences in Supplementary file 2). Enzymatic clean-up with Exonuclease I and

204 FastAP Thermosensitive Alkaline Phosphatase (Thermo Scientific) was carried out and subsequent

205 sequencing performed. PCR primers were used for sequencing along with BigDye Terminator v.1.1

206 cycle sequencing kit (Applied Biosystems). Cycling conditions were as follows: $94^{\circ} \mathrm{C}(1 \mathrm{minute})$;

$20794^{\circ} \mathrm{C}$ (30 seconds), $50^{\circ} \mathrm{C}\left(15\right.$ seconds), $60^{\circ} \mathrm{C}$ ( 4 minutes) for 25 cycles. Sequencing reaction 
208 products were purified using sephadex columns and then run on a 3730xI DNA Analyzer. The

209

210

211

212

213

214 Variant genotyping and statistical analysis

215 The SBF2 variant was genotyped using an allelic discrimination assay using an ABI StepOne real-

216 time thermal cycler. Primers and allelic discrimination probes were designed using Primer3 [27] and

217 obtained from Integrated DNA Technologies (IDT). Primer sequences were:

218 TGGGAGAGTGGAAGCAACAG (forward); GGAGTGTCTCTGTATGTGCACATT (reverse); 5'-

219 FAM- TTGTCACAAACAGTTACCAA-NFQ-3' (mutant); 5'-VIC- TTGTCACAAACAGGTACCAA-

220

221

222

223

224

225

226

227

228

229

230

231

232

233

234

235

236

237

238

239

240

241

NFQ-3' (wildtype). Individual probe assays were re-suspended in ultrapure water to a 40X mix and combined. Allelic discrimination reactions were prepared using KAPA probe fast (KAPA Biosystems) with the $40 \mathrm{X}$ probe mix. Thermal cycling conditions were: $25^{\circ} \mathrm{C}$ for 30 seconds; $95^{\circ} \mathrm{C}$ for 3 minutes; followed by 40 cycles of $95^{\circ} \mathrm{C}$ for 3 seconds; and $60^{\circ} \mathrm{C}$ for 10 seconds, then the reaction held at $25^{\circ} \mathrm{C}$ for 30 seconds.

As the variant was rare in our sample set, a subset of genotypes was verified by Sanger sequencing. Primer sequences were AACCTCATGGTCAACCTGCT (forward) and TGCACAGCAGTATTTGCCTAA (reverse). PCR cycling consisted of an initial $95^{\circ} \mathrm{C}$ denaturation step for 5 minutes, followed by 35 cycles of $95^{\circ} \mathrm{C}$ for 30 seconds; $60^{\circ} \mathrm{C}$ for 30 seconds; and $72^{\circ} \mathrm{C}$ for 1 minute. Final elongation was $72^{\circ} \mathrm{C}$ for 5 minutes. PCR products were purified using 96-well multiscreen PCR plates (Merk Millipore) and sequenced in both directions using BigDye Terminator v3.1 chemistry (Applied Biosystems) and an ABI 3130XL Genetic Analyzer (Applied Biosystems). Sequences were aligned and manually called using the Staden package [28].

The association between demyelinating neuropathy and genotype was assessed using the Fisher's exact test.

\section{Immunohistochemistry of peripheral nerve sections}

Peripheral nerve specimens originating from surgical biopsies at the time of diagnosis were embedded in OCT and snap frozen in isopentane pre-cooled with liquid nitrogen and stored at $80^{\circ} \mathrm{C}$. Cryostat sections of $30 \mu \mathrm{m}$ were then cut and mounted on histopathology slides and air 
242 dried for 30 minutes at $37^{\circ} \mathrm{C}$. The sections were stained for myelin basic protein as follows:

243 incubation in a blocking solution of $10 \%$ normal goat serum $0.1 \mathrm{M}$ PBS and $0.3 \% \mathrm{t}-$

244 octylphenoxypolyethoxyethanol for an hour at room temperature; incubation with primary

245 antibody (anti-myelin basic protein monoclonal antibody, 1:100, Chemicon) diluted in 0.1M PBS

246 containing normal goat serum overnight at $4^{\circ} \mathrm{C}$; washing 3 times with $0.1 \mathrm{M} \mathrm{PBS}$ for 5 minutes;

247 incubation with a secondary antibody (Alex Fluor 488, goat anti-rat, ThermoFischer Scientific)

248 for 2 hours, in the dark, at room temperature. The sections were then examined under a

249 fluorescent microscope.

250

251

252

253

254

255

256

257

258

259

260

261

262

263

264

265

266

267

268

269

270

271

272

273

274

275

276

\section{Results}

\section{Disease phenotype}

The phenotype of this inherited demyelinating peripheral nerve disease was previously reported and affected dogs share familial links, based on the pedigree analysis of 32 dogs (see Figure 2 from Vanhaesebrouck et al.) [25]. Briefly, at a young age (<2 years), affected Miniature Schnauzers presented regurgitations caused by mega-esophagus and inspiratory dyspnea caused by laryngeal paralysis. Electrophysiological studies revealed marked slowing of motor and sensory nerve conduction velocities ( $20 \mathrm{~m} / \mathrm{s}$ ), although some nerves had preserved conduction velocities. Although the prognosis remains guarded, long survival is observed with dogs alive $>3$ years following diagnosis. Teased nerve fibers presented variable thickness of the myelin sheath with characteristic 'tomacula' and area of segmental demyelination. Toluidine-blue-stained semi-thick resin-embedded sections demonstrated loss of myelinated fibers, thinly myelinated fibers and redundant myelin loops again characteristic of the presence of tomacula, as previously reported by Vanhaesebrouck et al. [25]. Muscle biopsy specimens appeared normal when sampled [25]. Immunohistochemistry of peripheral nerve sections stained for myelin basic protein (Fig. 1) demonstrate the loss of normal myelin architecture in affected cases.

\section{Mapping of the causative variant}

The genome-wide association study was conducted using two cases originally described in 2008 [25] and 38 apparently healthy breed-matched controls (one control sample did not work during testing). The strongest associated SNP was located on canine chromosome 21 (BICF2S2377579 - CanFam 3.1 position chr21: 34,045,084) (Fig. 2), although this did not reach genome-wide statistical association due to the small dataset and concurrent lack of statistical power. Interrogation of the SNP genotype distributions across the associated region identified a 
277 run of shared homozygosity in cases spanning from chr21:18,552,117-46,804,230

278 (CanFam3.1). The most obvious candidate gene in this region was the SBF2 gene, which

279 causes CMT in human patients with a clear phenotype.

280

281 Resequencing of the SBF2 gene was initially performed using one of the two affected case and 282 one control. This revealed a homozygous +1 splice genetic variant in exon 19 (c.2363+1 G>T; 283 chr21:33,080,022 C>A CanFam3.1) in the affected case in comparison to the control (Fig. 3).

284 No further variants were found in the entire coding sequence. This putative disease-causing 285 c.2363+1 G>T variant was assessed in the initial GWAS set (2 affected and 39 controls) plus six 286 additional affected cases and a further 192 Miniature Schnauzers with no report of the disorder, 287 demonstrating a highly significant statistical association (see Table 1) in comparison to the top 288 GWAS SNP. This identified 10 heterozygotes and 182 dogs with a homozygous wildtype 289 genotype in the added 192 controls and 38 homozygous wildtype genotypes in the GWAS set 290 (one control from this set did not work); but no dogs homozygous for the variant in the control 291 set. The 6 affected cases, 5 from Spain and one from Belgium, were mutant homozygous dogs. 292 Screening for the variant in a dataset of 802 whole genome sequences from 162 purebred 293 dogs/mixed breed dogs/wolves identified two Miniature Schnauzers that were heterozygous for 294 the variant and one mutant homozygote; the remaining 799 dogs were clear (Supplementary file 295 3). On follow-up investigation the mutant homozygous dog was affected with neonatal lethal spondylocostal dysostosis, hence no clinical data relevant to the demyelinating neuropathy phenotype was available [29]. The original two GWAS cases were found in France and the mutant homozygote identified through genome data was of Australian origin, although the sire was from Sweden. The additional six affected cases were from Spain and Belgium. This tentatively suggests presence of the variant in different regions of the globe.

\section{Effect of SBF2 variant on mRNA splicing and coding sequence}

To analyze the consequence of this splicing acceptor site variant on SBF2 pre-mRNA splicing, RNA was extracted from dissected muscle of an unaffected and an affected dog (the case found in Belgium) and RT-PCR performed. The resulting transcripts were sequenced which revealed the presence of a 40-bp deletion at the 3' site of exon 19 due to the induction of a cryptic splice site in this exon (Fig. 4A). The SBF2 genetic variant and resulting 40-bp deletion leads to a 308 premature stop codon (p.G775Vfs*5) and truncates the protein by 1070 amino acids (Fig. 4B).

309

310 


\section{Discussion}

312 We previously described a suspected inherited demyelinating peripheral neuropathy in

313 Miniature Schnauzer dogs and highlighted its similarities with some demyelinating forms of CMT

314 in humans [25, 30]. Mainly, we discovered in the dog the presence of specific neuropathological

315 features of the peripheral nerves, such as abnormal folding of peripheral myelin around the

316 axons termed tomacula, as originally described in humans with certain demyelinating

317 neuropathies [31, 32]. An inherited trait for the canine disease equivalent was suggested based

318 on pedigree analysis of affected dogs. Our findings led us to suspect that variants of genes

319 coding for: (i) myelin proteins (such as PMP22, P0, periaxin); (ii) intracellular Schwann cell

320 proteins involved in the synthesis, transport and degradation of myelin proteins including the

321 myotubularin-related (MTMR) proteins; and (iii) regulating myelin gene transcription proteins

322 (such as EGR2), might be responsible for the disease [33, 34]. In particular, variants of genes

323 coding for the MTMR proteins and leading to abnormal myelin compaction have been described

324 in CMT type 1, type 4B1 (variants in MTMR2) and type 4B2 (variant in SBF2 (MTMR13),

325 MTMR2 regulatory binding partner) [33, 35-51]. In this study we have mapped demyelinating

326 neuropathy in the Miniature Schnauzer to canine chromosome 21 and have subsequently

327 identified a genetic variant in and exon 19 of SBF2 that shows strong segregation with the

328 disease in this breed. Variants of the SBF2 gene are known in humans to cause CMT type 4B2

329 (although a variant in exon 19 has not been found in humans). So far, thirty-seven humans with

330 twenty-six pathogenic SBF2 variants leading to CMT type 4B2 have been reported [52], a

331 number that has dramatically increased recently with the discovery of nine new SBF2 variants in

332 one study [49] and three new SBF2 variants in another [48].

333 Myotubularins (MTM) form a family of 14 proteins [53] that act as phosphoinositide phosphatase

334 (PP) proteins and play a central role in neuromuscular homeostasis [39]. Some are catalytically

335 active (such as MTRM2) and dephosphorylate sub pools of phosphatidylinositols (Ptdlns) [53-

336 57], while others are catalytically inactive and function as a scaffold to bind other myotubularins

337 and proteins (such as MTMR13 binds MTMR2) [58, 59]. They are implicated in a number of

338 physiological processes including cell proliferation, growth, survival, motility, cytoskeletal

339 regulation and intracellular vesicle trafficking and signaling (endosomal-lysosomal pathways)

$340[53,60]$. Their importance is highlighted by the large number of diseases associated with variant

341 of myotubularin genes [61-63], but it remains poorly understood how these variants lead to

342 disease.

343 Their ubiquitous expression, lack of functional redundancy and involvement in varied

344 pathologies suggests that their expression and regulation finely varies between organs [64, 65]. 
345 For example, in humans, a variant within the dDENN domain of SBF2 leads to a demyelinating

346

347

348

349

350

351

352

353

354

355

356

357

358

359

360

361

362

363

364

365

366

367

368

369

370

371

372

373

374

375

376

377

378

neuropathy [39] and a variant within the DENN domain causes a thrombocytopenia without neurological manifestations [47]. It is believed in this latter case that the genetic variant affects the solubility of the SBF2 protein but that the protein conformation is preserved [47]. In cases with involvement of the peripheral nerves, the analysis of the type of genetic variants associated with SBF2 also provides a very good example of how variants in one gene, and within a particular domain, leads to different phenotypes, in particular with additional involvement of the eye. The first SBF2 variant in humans was reported in a Turkish family and involved a deletion of 1,301 bp across exons 11 and 12, removing the unique dDENN motif [39] but allowing the synthesis of a partially functional SBF2 protein highlighting the possible role of dDENN in myelin compaction. This only caused a demyelinating neuropathy. Later, in a Tunisian and a Moroccan family, two nonsense variants in SBF2 were identified in exons 23 (2875C > T (Gln956Stop)) and 27 (3586C > T (Arg1196Stop)) [40]. These patients presented juvenile onset glaucoma associated with the demyelinating neuropathy, a phenotype that was also found in a Japanese family affected by another nonsense variant (1459C >T (Arg487Stop)) in exon 14 of SBF2 gene [41]. These variants resulted in a truncated protein with deletion of the GRAM, myotube-related and PH domains and complete loss of function. Finally, with variants of the inactive phosphatase domain of $S B F 2$, leading to presence of an abnormal but likely partially functional SBF2 protein, human patients have a demyelinating peripheral neuropathy with or without glaucoma [42, 49]. The occurrence of ocular anomalies in association with peripheral neuropathy is also present in the recent report of an inherited peripheral neuropathy in Black Russian terrier dogs [18].

The finding of a variant in SBF2 in the dogs of this report strikingly exemplifies the wide role of myotubularin proteins since a variant of MTM1 has also been reported in a group of Labrador Retrievers, but leads to a centro-nuclear myopathy [66], as it does in humans [64]. These dogs are clinically normal at birth but develop generalized muscular weakness and muscle atrophy at $\sim 7$ weeks of age and die in their first six months of life. MTM1 is specifically involved in endosomal and membrane trafficking pathways, and late maturation and maintenance of Ttubules. In affected dogs, the structure of the T tubule network is affected, leading to disorganization of the muscle triads and their maintenance.

377 This new Miniature Schnauzer canine model allows useful comparisons between the human and canine disease for several reasons. First, this is a spontaneous (i.e. naturally occurring)

Peer) reviewing PDF | (2019:04:37233:1:1:NEW 26 Sep 2019) 
379 model of a demyelinating neuropathy with focally folded myelin. This is important because the 380 phenotype is likely more relevant and closer to the disease observed in humans, knowing the 381 limitations of the rodent models. SBF2 deficient mice have been created by inserting a gene382 trap vector following exon 14 of SBF2, leading to lack of expression of the PH-GRAM and 383 phosphatase domains and coiled-coil motif of SBF2 [67], which are the domains involved in 384 binding, catalyzing and mediating interactions between active and inactive myotubularins [68, 385 69]. Although SBF2 is broadly expressed in the mouse [70], the phenotype of this model differs 386 from the naturally occurring disease since no reduction in the sciatic nerve conduction velocity 387 was observed at 12 months of age in mice (this is also the case in a mouse model of the 388 MTMR2 neuropathy [71]), which markedly contrasts with the profound slowing of nerve 389 conduction velocity observed in dogs [35] and humans [39-42]. Clinically, these mice are not 390 distinguishable from wild type animals but behavior analysis with the rotarod test identified 391 deficient mice [67].

392 Another group of researchers created a similar mouse mutant by inserting a gene-trap plasmid 393 following exon 17 [72], resulting in a similar defect as described above. Again, these animals did 394 not show obvious behavioral abnormalities, but in contrast to the model from Tersar et al. [67], 395 showed reduced motor nerve conduction velocities (in the range of $20 \mathrm{~m} / \mathrm{s}$ ). These two examples 396 illustrate the complexity of establishing engineered animal models in the laboratory because the 397 clinical phenotype obtained is not predictable, or is variable or lacking. In contrast, affected 398 Miniature Schnauzer dogs present to veterinary hospitals with clear clinical signs, marked 399 electrophysiological abnormalities and characteristic pathological features. As shown above, the 400 variant described can be directly compared to variants affecting some human families, where protein abnormalities are more likely to be similar. Altogether, the signs observed in dogs provide means to follow-up the disease progression and to trial novel therapies. Secondly, the dog model could be used for in vitro studies, for example using fibroblast cultures that can be easily obtained from skin biopsies. In one study [73] using the Robinson's mouse model [72], the consequences of SBF2 variant on the endo-lysosomal pathway has been investigated and it was found that loss of SBF2 does not dysregulate the endo-lysosomal membrane system in Schwann cells. Therefore, there is a need to further identify the impact of SBF2 loss on the trafficking of specific cargo proteins. The prevalence of the disease in Miniature Schnauzers is currently not known but there is likely a pool of animals that could be available for tissue sampling and further in vitro research. Future studies could focus on the identification of specific membrane proteins that may be abnormally trafficked in the absence of SBF2, as well as on defining how phosphatidylinositols are dysregulated by the loss of these proteins [74]. Finally, it 
413 should be mentioned that, although spontaneous canine models are appealing, they come with

414 limitations. In particular, their remain unknown as to how many cases could be accessed for

415 research. The use of companion dogs in research requires strict ethical safeguards, and

416 imposes limitation to access to tissue (including post-mortem) and interventions that can be

417 performed. The cost of developing colonies of affected dogs within veterinary laboratories and

418 cost of running clinical trial is also greater than the cost of working with rodents.

419

420

421

422

423

424

425

426

427

428

429

\section{Conclusions}

In conclusion, we have identified a splicing variant in SBF2 as the most likely cause for the demyelinating peripheral neuropathy observed in Miniature Schnauzer dogs. This provides the first naturally occurring large animal model of a demyelinating form of CMT disease, 4B2.

The discovery and description of naturally occurring models of CMT diseases open great research avenues. They render possible in vitro characterization of molecular pathways and functional work, such as with the use of fibroblasts obtained from the skin or nerve transcriptome analysis. The large pool of affected dogs and expansion of veterinary hospitals could allow collection of samples for this research and could pave the way for testing new therapies in canine models, as exemplified by the recent use of gene editing to restore dystrophin expression in a canine model of muscular dystrophy [75]. This strategy could be applied to many genetic diseases, such as the demyelinating peripheral neuropathy presented here, while the use of a larger animal model allows real-life quantification of the benefit of proposed therapies.

436

437

\section{Acknowledgements}

The authors are grateful to referring veterinarians, veterinary neurology specialists (Sofie Bhatti,

441 Prof. Luc VanHam, Dr. An Vanhaesbrouck, Jerome Couturier, Laurent Cauzinille, Prof. Diane

442 Shelton) and to all dog owners and breeders who donated samples and shared pedigree data of 443 their dogs. We thank the Joint Miniature Schnauzer Eye Fund for funding the genome-wide 444 association study of the 32 dogs in the Animal Health Trust dataset. We thank the Dog 445 Biomedical Variant Database Consortium (Gus Aguirre, Catherine André, Danika Bannasch, 446 Doreen Becker, Brian Davis, Cord Drögemüller, Kari Ekenstedt, Kiterie Faller, Oliver Forman, 447 Steve Friedenberg, Eva Furrow, Urs Giger, Christophe Hitte, Marjo Hytönen, Vidhya 448 Jagannathan, Tosso Leeb, Hannes Lohi, Cathryn Mellersh, Jim Mickelson, Leonardo Murgiano, 
449

450

451

452

453

454

455

456

457

458

459

460

461

462

463

464

465

466

467

468

469

470

471

472

473

474

475

476

477

478

479

480

481

482

483

484

485

486

487

488

489

490

491

492

493

494

495

Anita Oberbauer, Sheila Schmutz, Jeffrey Schoenebeck, Kim Summers, Frank van Steenbeek, Claire Wade) and Natasha Olby for sharing whole genome sequencing data from control dogs.

We also acknowledge all canine researchers who deposited dog whole genome sequencing data into public databases. We also thank the breed clubs and Kennel Club Charitable Trust who jointly funded the Animal Health Trust's Give a Dog a Genome project that contributed data from control dogs.

\section{References}

1. Skre H: Genetic and clinical aspects of Charcot-Marie-Tooth's disease. Clin Genet 1974, 6(2):98-118.

2. Pareyson D, Marchesi C: Diagnosis, natural history, and management of Charcot-MarieTooth disease. Lancet Neurol 2009, 8(7):654-667.

3. Reilly MM, Murphy SM, Laura M: Charcot-Marie-Tooth disease. J Peripher Nerv Syst 2011, 16(1):1-14.

4. $\quad$ Emery AE: Population frequencies of inherited neuromuscular diseases--a world survey. Neuromuscul Disord 1991, 1(1):19-29.

5. Charcot JM: Sur une forme particulière d'atrophie musculaire progressive, souvent familiale, débutant par les pieds et les jambes et atteignant plus tard les mains. Revue médicale 1886, 6:97-138.

6. Vallat JM, Mathis S, Funalot B: The various Charcot-Marie-Tooth diseases. Curr Opin Neurol 2013, 26(5):473-480.

7. Houlden $\mathrm{H}$, Reilly MM: Molecular genetics of autosomal-dominant demyelinating Charcot-Marie-Tooth disease. Neuromolecular Med 2006, 8(1-2):43-62.

8. Bouhy D, Timmerman V: Animal models and therapeutic prospects for Charcot-MarieTooth disease. Ann Neurol 2013, 74(3):391-396.

9. Coates JR, O'Brien DP: Inherited peripheral neuropathies in dogs and cats. Vet Clin North Am Small Anim Pract 2004, 34(6):1361-1401.

10. Granger N: Canine inherited motor and sensory neuropathies: an updated classification in 22 breeds and comparison to Charcot-Marie-Tooth disease. Vet J 2011, 188(3):274285.

11. Forman OP, De Risio L, Mellersh CS: Missense mutation in CAPN1 is associated with spinocerebellar ataxia in the Parson Russell Terrier dog breed. PloS one 2013, 8(5):e64627.

12. Fenn J, Boursnell M, Hitti RJ, Jenkins CA, Terry RL, Priestnall SL, Kenny PJ, Mellersh CS, Forman OP: Genome sequencing reveals a splice donor site mutation in the SNX14 gene associated with a novel cerebellar cortical degeneration in the Hungarian Vizsla dog breed. BMC genetics 2016, 17(1):123.

13. Baranowska I, Jaderlund KH, Nennesmo I, Holmqvist E, Heidrich N, Larsson NG, Andersson G, Wagner EG, Hedhammar A, Wibom R, Andersson L: Sensory ataxic neuropathy in golden retriever dogs is caused by a deletion in the mitochondrial tRNATyr gene. PLoS Genet 2009, 5(5):e1000499.

14. Bruun CS, Jaderlund $K H$, Berendt $M$, Jensen $K B$, Spodsberg $E H$, Gredal $H$, Shelton GD, Mickelson JR, Minor KM, Lohi H, Bjerkås I, Stigen O, Espenes A, Rohdin C, Edlund R, Ohlsson J, Cizinauskas S, Leifsson PS, Drögemüller C, Moe L, Cirera S, Fredholm M: A Gly98Val mutation in the N-Myc downstream regulated gene 1 (NDRG1) in Alaskan Malamutes with polyneuropathy. PloS one 2013, 8(2):e54547.

Peer] reviewing PDF | (2019:04:37233:1:1:NEW 26 Sep 2019) 
496

497

498

499

500

501

502

503

504

505

506

507

508

509

510

511

512

513

514

515

516

517

518

519

520

521

522

523

524

525

526

527

528

529

530

531

532

533

534

535

536

537

538

539

540

541

542

543

544

545

546

15. Drogemuller C, Becker D, Kessler B, Kemter E, Tetens J, Jurina K, Jaderlund KH, Flagstad A, Perloski M, Lindblad-Toh K, Matiasek K: A deletion in the N-myc downstream regulated gene 1 (NDRG1) gene in Greyhounds with polyneuropathy. PloS one 2010, 5(6):e11258.

16. Ekenstedt KJ, Becker D, Minor KM, Shelton GD, Patterson EE, Bley T, Oevermann A, Bilzer T, Leeb T, Drogemuller C, Mickelson JR: An ARHGEF10 deletion is highly associated with a juvenile-onset inherited polyneuropathy in Leonberger and Saint Bernard dogs. PLoS genetics 2014, 10(10):e1004635.

17. Becker D, Minor KM, Letko A, Ekenstedt KJ, Jagannathan V, Leeb T, Shelton GD, Mickelson JR, Drogemuller C: A GJA9 frameshift variant is associated with polyneuropathy in Leonberger dogs. BMC genomics 2017, 18(1):662.

18. Mhlanga-Mutangadura T, Johnson GS, Schnabel RD, Taylor JF, Johnson GC, Katz ML, Shelton GD, Lever TE, Giuliano E, Granger N, Shomper J, O'Brien DP: A mutation in the Warburg syndrome gene, RAB3GAP1, causes a similar syndrome with polyneuropathy and neuronal vacuolation in Black Russian Terrier dogs. Neurobiology of disease 2016, 86:75-85.

19. Wiedmer M, Oevermann A, Borer-Germann SE, Gorgas D, Shelton GD, Drogemuller M, Jagannathan V, Henke D, Leeb T: A RAB3GAP1 SINE Insertion in Alaskan Huskies with Polyneuropathy, Ocular Abnormalities, and Neuronal Vacuolation (POANV) Resembling Human Warburg Micro Syndrome 1 (WARBM1). G3 2015, 6(2):255-262.

20. Mhlanga-Mutangadura T, Johnson GS, Ashwini A, Shelton GD, Wennogle SA, Johnson GC, Kuroki K, O'Brien DP: A Homozygous RAB3GAP1:c.743delC Mutation in Rottweilers with Neuronal Vacuolation and Spinocerebellar Degeneration. Journal of veterinary internal medicine 2016, 30(3):813-818.

21. Wheeler SJ: Sensory neuropathy in a Border Collie Puppy. J Small Anim 1987, 28:281289.

22. Forman OP, Hitti RJ, Pettitt L, Jenkins CA, O'Brien DP, Shelton GD, De Risio L, Quintana RG, Beltran E, Mellersh C: An Inversion Disrupting FAM134B Is Associated with Sensory Neuropathy in the Border Collie Dog Breed. G3 (Bethesda) 2016, 6(9):2687-2692.

23. Amengual-Batle P, Rusbridge C, José-López R, Golini L, Shelton GD, Mellersh CS, Gutierrez-Quintana R: Two mixed breed dogs with sensory neuropathy are homozygous for an inversion disrupting FAM134B previously identified in Border Collies. Journal of veterinary internal medicine 2018, 32(6):2082-2087.

24. Plassais J, Lagoutte L, Correard S, Paradis M, Guaguère E, Hédan B, Pommier A, Botherel N, Cadiergues MC, Pilorge P, Silversides D, Bizot M, Samuels M, Arnan C, Johnson R, Hitte C, Salbert G, Méreau A, Quignon P, Derrien T, André C: A Point Mutation in a lincRNA Upstream of GDNF Is Associated to a Canine Insensitivity to Pain: A Spontaneous Model for Human Sensory Neuropathies. PLoS Genet 2016, 29;12(12):e1006482.

25. Vanhaesebrouck AE, Couturier J, Cauzinille L, Mizisin AP, Shelton GD, Granger N: Demyelinating polyneuropathy with focally folded myelin sheaths in a family of Miniature Schnauzer dogs. J Neurol Sci 2008, 275(1-2):100-105.

26. Purcell S, Neale B, Todd-Brown K, Thomas L, Ferreira MA, Bender D, Maller J, Sklar P, de Bakker PI, Daly MJ, Sham PC: PLINK: a tool set for whole-genome association and population-based linkage analyses. American journal of human genetics 2007, 81(3):559-575.

27. Untergasser A, Cutcutache I, Koressaar T, Ye J, Faircloth BC, Remm M, Rozen SG: Primer3--new capabilities and interfaces. Nucleic acids research 2012, 40(15):e115.

28. Staden R: The Staden sequence analysis package. Molecular biotechnology 1996, 5(3):233-241.

Peer) reviewing PDF | (2019:04:37233:1:1:NEW 26 Sep 2019) 
547

548

549

550

551

552

553

554

555

556

557

558

559

560

561

562

563

564

565

566

567

568

569

570

571

572

573

574

575

576

577

578

579

580

581

582

583

584

585

586

587

588

589

590

591

592

593

594

595

596

29. Willet CE, Makara M, Reppas G, Tsoukalas G, Malik R, Haase B, Wade CM: Canine disorder mirrors human disease: exonic deletion in HES7 causes autosomal recessive spondylocostal dysostosis in miniature Schnauzer dogs. PloS one 2015, 10(2):e0117055.

30. Niemann A, Berger P, Suter U: Pathomechanisms of mutant proteins in Charcot-MarieTooth disease. Neuromolecular medicine 2006, 8(1-2):217-242.

31. Ohnishi A, Murai Y, Ikeda M, Fujita T, Furuya H, Kuroiwa Y: Autosomal recessive motor and sensory neuropathy with excessive myelin outfolding. Muscle Nerve 1989, 12(7):568-575.

32. Gabreels-Festen AA, Joosten EM, Gabreels FJ, Stegeman DF, Vos AJ, Busch HF: Congenital demyelinating motor and sensory neuropathy with focally folded myelin sheaths. Brain 1990, 113 ( Pt 6):1629-1643.

33. Previtali SC, Quattrini A, Bolino A: Charcot-Marie-Tooth type 4B demyelinating neuropathy: deciphering the role of MTMR phosphatases. Expert reviews in molecular medicine 2007, 9(25):1-16.

34. Suter U, Scherer SS: Disease mechanisms in inherited neuropathies. Nat Rev Neurosci 2003, 4(9):714-726.

35. Houlden H, King RH, Wood NW, Thomas PK, Reilly MM: Mutations in the 5 ' region of the myotubularin-related protein 2 (MTMR2) gene in autosomal recessive hereditary neuropathy with focally folded myelin. Brain 2001, 124(Pt 5):907-915.

36. Bolino A, Muglia M, Conforti FL, LeGuern E, Salih MA, Georgiou DM, Christodoulou K, Hausmanowa-Petrusewicz I, Mandich P, Schenone A, Gambardella A, Bono F, Quattrone A, Devoto M, Monaco AP: Charcot-Marie-Tooth type 4B is caused by mutations in the gene encoding myotubularin-related protein-2. Nat Genet 2000, 25(1):17-19.

37. Conforti FL, Muglia M, Mazzei R, Patitucci A, Valentino P, Magariello A, Sprovieri T, Bono F, Bergmann C, Gabriele AL, Peluso G, Nisticò R, Senderek J, Quattrone A: A new SBF2 mutation in a family with recessive demyelinating Charcot-Marie-Tooth (CMT4B2). Neurology 2004, 63(7):1327-1328.

38. Nelis E, Erdem S, Tan E, Lofgren A, Ceuterick C, De Jonghe P, Van Broeckhoven C, Timmerman V, Topaloglu H: A novel homozygous missense mutation in the myotubularin-related protein 2 gene associated with recessive Charcot-Marie-Tooth disease with irregularly folded myelin sheaths. Neuromuscul Disord 2002, 12(9):869873.

39. Senderek J, Bergmann C, Weber S, Ketelsen UP, Schorle H, Rudnik-Schoneborn S, Buttner R, Buchheim E, Zerres K: Mutation of the SBF2 gene, encoding a novel member of the myotubularin family, in Charcot-Marie-Tooth neuropathy type 4B2/11p15. Hum Mol Genet 2003, 12(3):349-356.

40. Azzedine H, Bolino A, Taieb T, Birouk N, Di Duca M, Bouhouche A, Benamou S, Mrabet A, Hammadouche T, Chkili T, Gouider R, Ravazzolo R, Brice A, Laporte J, LeGuern: Mutations in MTMR13, a new pseudophosphatase homologue of MTMR2 and Sbf1, in two families with an autosomal recessive demyelinating form of Charcot-Marie-Tooth disease associated with early-onset glaucoma. Am J Hum Genet 2003, 72(5):11411153.

41. Hirano R, Takashima H, Umehara F, Arimura H, Michizono K, Okamoto Y, Nakagawa M, Boerkoel CF, Lupski JR, Osame M, Arimura K: SET binding factor 2 (SBF2) mutation causes CMT4B with juvenile onset glaucoma. Neurology 2004, 63(3):577-580.

42. Luigetti M, Bolino A, Scarlino S, Sabatelli M: A novel homozygous mutation in the MTMR2 gene in two siblings with 'hypermyelinating neuropathy'. Journal of the peripheral nervous system : JPNS 2013, 18(2):192-194.

Peer) reviewing PDF | (2019:04:37233:1:1:NEW 26 Sep 2019) 
597

598

599

600

601

602

603

604

605

606

607

608

609

610

611

612

613

614

615

616

617

618

619

620

621

622

623

624

625

626

627

628

629

630

631

632

633

634

635

636

637

638

639

640

641

642

643

644

645

646

647
43. Murakami T, Kutoku Y, Nishimura H, Hayashi M, Abe A, Hayasaka K, Sunada Y: Mild phenotype of Charcot-Marie-Tooth disease type 4B1. J Neurol Sci 2013, 334(1-2):176179.

44. Nouioua S, Hamadouche T, Funalot B, Bernard R, Bellatache N, Bouderba R, Grid D, Assami S, Benhassine T, Levy N, Vallat JM, Tazir M: Novel mutations in the PRX and the MTMR2 genes are responsible for unusual Charcot-Marie-Tooth disease phenotypes. Neuromuscul Disord 2011, 21(8):543-550.

45. Parman Y, Battaloglu E, Baris I, Bilir B, Poyraz M, Bissar-Tadmouri N, Williams A, Ammar N, Nelis E, Timmerman V, De Jonghe P, Najafov A, Deymeer F, Serdaroglu P, Brophy PJ, Said G: Clinicopathological and genetic study of early-onset demyelinating neuropathy. Brain 2004, 127(Pt 11):2540-2550.

46. Verny C, Ravise N, Leutenegger AL, Pouplard F, Dubourg O, Tardieu S, Dubas F, Brice A, Genin E, LeGuern E: Coincidence of two genetic forms of Charcot-Marie-Tooth disease in a single family. Neurology 2004, 63(8):1527-1529.

47. Abuzenadah AM, Zaher GF, Dallol A, Damanhouri GA, Chaudhary AG, Al-Sayes F, Gari MA, AlZahrani M, Hindawi S, Al-Qahtani MH: Identification of a novel SBF2 missense mutation associated with a rare case of thrombocytopenia using whole-exome sequencing. Journal of thrombosis and thrombolysis 2013, 36(4):501-506.

48. He J, Guo L, Xu G, Xu L, Lin S, Chen W, Wang N: Clinical and genetic investigation in Chinese patients with demyelinating Charcot-Marie-Tooth disease. Journal of the peripheral nervous system : JPNS 2018.

49. Laššuthová $P$, Vill K, Erdem-Ozdamar S, Schröder JM, Topaloglu H, Horvath R, MüllerFelber W, Bansagi B, Schlotter-Weigel B, Gläser D, Neupauerová J, Sedláčková L, Staněk D, Mazanec R, Weis J, Seeman P, Senderek J: Novel SBF2 mutations and clinical spectrum of Charcot-Marie-Tooth neuropathy type 4B2. Clinical genetics 2018, 94(5):467-472.

50. Negrao L, Almendra L, Ribeiro J, Matos A, Geraldo A, Pinto-Basto J: Charcot-MarieTooth 4B2 caused by a novel mutation in the MTMR13/SBF2 gene in two related Portuguese families. Acta myologica : myopathies and cardiomyopathies : official journal of the Mediterranean Society of Myology 2014, 33(3):144-148.

51. Chen M, Wu J, Liang N, Tang L, Chen Y, Chen H, Wei W, Wei T, Huang H, Yi X, Qi M: Identification of a novel SBF2 frameshift mutation in charcot-marie-tooth disease type 4B2 using whole-exome sequencing. Genomics, proteomics \& bioinformatics 2014, 12(5):221-227.

52. Baets J, Deconinck T, De Vriendt E, Zimoń M, Yperzeele L, Van Hoorenbeeck K, Peeters K, Spiegel R, Parman Y, Ceulemans B, Van Bogaert P, Pou-Serradell A, Bernert G, Dinopoulos A, Auer-Grumbach M, Sallinen SL, Fabrizi GM, Pauly F, Van den Bergh P, Bilir B, Battaloglu E, Madrid RE, Kabzińska D, Kochanski A, Topaloglu H, Miller G, Jordanova A, Timmerman V, De Jonghe P: Genetic spectrum of hereditary neuropathies with onset in the first year of life. Brain : a journal of neurology 2011, 134(Pt 9):2664-2676.

53. Laporte J, Bedez F, Bolino A, Mandel JL: Myotubularins, a large disease-associated family of cooperating catalytically active and inactive phosphoinositides phosphatases. Hum Mol Genet 2003, 12 Spec No 2:R285-292.

54. Biancalana V, Caron O, Gallati S, Baas F, Kress W, Novelli G, D'Apice MR, LagierTourenne C, Buj-Bello A, Romero NB, Mandel JL: Characterisation of mutations in 77 patients with $\mathrm{X}$-linked myotubular myopathy, including a family with a very mild phenotype. Hum Genet 2003, 112(2):135-142.

55. Blondeau F, Laporte J, Bodin S, Superti-Furga G, Payrastre B, Mandel JL: Myotubularin, a phosphatase deficient in myotubular myopathy, acts on phosphatidylinositol 3-kinase and phosphatidylinositol 3-phosphate pathway. Hum Mol Genet 2000, 9(15):2223-2229. 
648 56. Laporte J, Blondeau F, Buj-Bello A, Mandel JL: The myotubularin family: from genetic

649

650

651

652

653

654

655

656

657

658

659

660

661

662

663

664

665

666

667

668

669

670

671

672

673

674

675

676

677

678

679

680

681

682

683

684

685

686

687

688

689

690

691

692

693

694

695

696

697

698

57. Schaletzky J, Dove SK, Short B, Lorenzo O, Clague MJ, Barr FA: Phosphatidylinositol-5phosphate activation and conserved substrate specificity of the myotubularin phosphatidylinositol 3-phosphatases. Curr Biol 2003, 13(6):504-509.

58. Berger P, Berger I, Schaffitzel C, Tersar K, Volkmer B, Suter U: Multi-level regulation of myotubularin-related protein-2 phosphatase activity by myotubularin-related protein13/set-binding factor-2. Hum Mol Genet 2006, 15(4):569-579.

59. Jean S, Cox S, Schmidt EJ, Robinson FL, Kiger A: Sbf/MTMR13 coordinates PI(3)P and Rab21 regulation in endocytic control of cellular remodeling. Mol Biol Cell 2012, 23(14):2723-2740.

60. Buj-Bello A, Laugel V, Messaddeq N, Zahreddine H, Laporte J, Pellissier JF, Mandel JL: The lipid phosphatase myotubularin is essential for skeletal muscle maintenance but not for myogenesis in mice. Proc Natl Acad Sci U S A 2002, 99(23):15060-15065.

61. Amoasii L, Hnia K, Laporte J: Myotubularin phosphoinositide phosphatases in human diseases. Curr Top Microbiol Immunol 2012, 362:209-233.

62. McCrea HJ, De Camilli P: Mutations in phosphoinositide metabolizing enzymes and human disease. Physiology (Bethesda) 2009, 24:8-16.

63. Nicot AS, Laporte J: Endosomal phosphoinositides and human diseases. Traffic 2008, 9(8):1240-1249.

64. Kim SA, Taylor GS, Torgersen KM, Dixon JE: Myotubularin and MTMR2, phosphatidylinositol 3-phosphatases mutated in myotubular myopathy and type 4B Charcot-Marie-Tooth disease. J Biol Chem 2002, 277(6):4526-4531.

65. Laporte J, Liaubet L, Blondeau F, Tronchere H, Mandel JL, Payrastre B: Functional redundancy in the myotubularin family. Biochem Biophys Res Commun 2002, 291(2):305-312.

66. Beggs AH, Bohm J, Snead E, Kozlowski M, Maurer M, Minor K, Childers MK, Taylor SM, Hitte C, Mickelson JR, Guo LT, Mizisin AP, Buj-Bello A, Tiret L, Laporte J, Shelton GD: MTM1 mutation associated with X-linked myotubular myopathy in Labrador Retrievers. Proc Natl Acad Sci U S A 2010, 107(33):14697-14702.

67. Tersar K, Boentert M, Berger P, Bonneick S, Wessig C, Toyka KV, Young P, Suter U: Mtmr13/Sbf2-deficient mice: an animal model for CMT4B2. Human molecular genetics 2007, 16(24):2991-3001.

68. Begley MJ, Taylor GS, Brock MA, Ghosh P, Woods VL, Dixon JE: Molecular basis for substrate recognition by MTMR2, a myotubularin family phosphoinositide phosphatase. Proc Natl Acad Sci U S A 2006, 103(4):927-932.

69. Robinson FL, Dixon JE: The phosphoinositide-3-phosphatase MTMR2 associates with MTMR13, a membrane-associated pseudophosphatase also mutated in type 4B Charcot-Marie-Tooth disease. J Biol Chem 2005, 280(36):31699-31707.

70. Kirfel J, Senderek J, Moser M, Roper A, Stendel C, Bergmann C, Zerres K, Buettner R: Cloning, expression and characterization of the murine orthologue of SBF2, the gene mutated in Charcot-Marie-Tooth disease type 4B2. Gene expression patterns : GEP 2006, 6(8):978-984.

71. Bonneick S, Boentert M, Berger P, Atanasoski S, Mantei N, Wessig C, Toyka KV, Young $\mathrm{P}$, Suter U: An animal model for Charcot-Marie-Tooth disease type 4B1. Hum Mol Genet 2005, 14(23):3685-3695.

72. Robinson FL, Niesman IR, Beiswenger KK, Dixon JE: Loss of the inactive myotubularinrelated phosphatase Mtmr13 leads to a Charcot-Marie-Tooth 4B2-like peripheral neuropathy in mice. Proc Natl Acad Sci U S A 2008, 105(12):4916-4921.

73. $\mathrm{Ng}$ AA, Logan AM, Schmidt EJ, Robinson FL: The CMT4B disease-causing phosphatases Mtmr2 and Mtmr13 localize to the Schwann cell cytoplasm and

Peer) reviewing PDF | (2019:04:37233:1:1:NEW 26 Sep 2019) 
699

700

701

702

703

704

705

706

707 endomembrane compartments, where they depend upon each other to achieve wild-type levels of protein expression. Hum Mol Genet 2013, 22(8):1493-1506.

74. Dang H, Li Z, Skolnik EY, Fares H: Disease-related myotubularins function in endocytic traffic in Caenorhabditis elegans. Molecular biology of the cell 2004, 15(1):189-196.

75. Amoasii L, Hildyard JCW, Li H, Sanchez-Ortiz E, Mireault A, Caballero D, Harron R, Stathopoulou TR, Massey C, Shelton JM, Bassel-Duby R, Piercy RJ, Olson EN: Gene editing restores dystrophin expression in a canine model of Duchenne muscular dystrophy. Science 2018, 362(6410):86-91 . 


\section{Figure 1}

Immunofluorescent staining for myelin basicprotein in canine peripheral nerves.

(A, C) Transverse sections ( $30 \mu \mathrm{m}$ ) obtained from the tibial nerve of a normal Miniature Schnauzer dog stained for myelin basic protein (green) - note the preservation of the peripheral myelin architecture delineating axons within the fascicle; $(B, D)$ Transverse sections $(30 \mu \mathrm{m})$ obtained from the tibial nerve of an affected Miniature Schnauzer dog - the myelin has lost its organization. $C$ and $D$ are magnified images of $A$ and $B$ white rectangles respectively. Scale bar A, C $=20 \mu \mathrm{m}$; scale bar B, D = $10 \mu \mathrm{m}$.

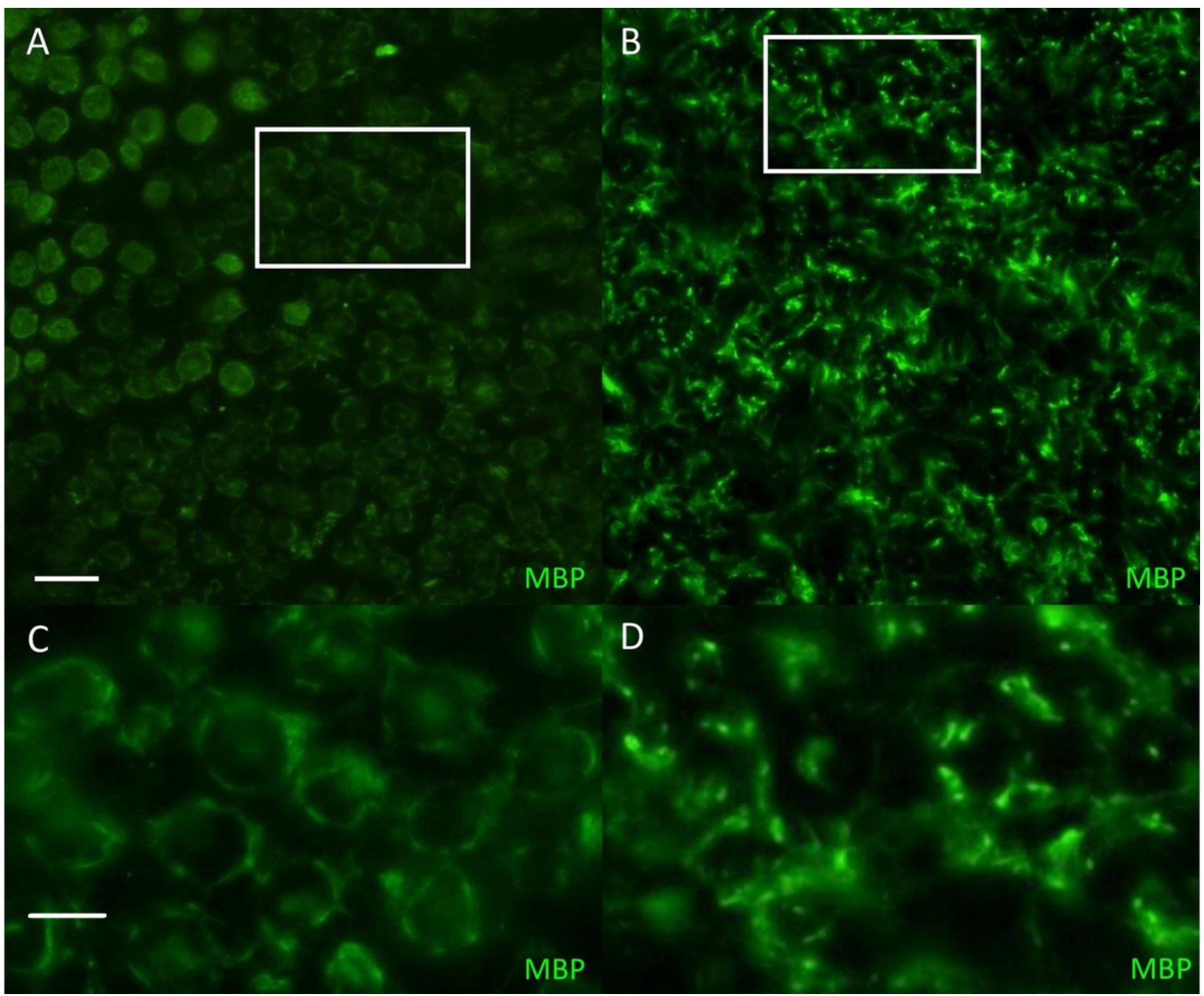




\section{Table $\mathbf{1}$ (on next page)}

Miniature Schnauzers genotyped for the candidate variant originating from the initial GWAS set ( 2 affected cases and 38 controls*), 6 other affected cases and 192 controls. 
Table 1 Miniature Schnauzers genotyped for the candidate variant originating from the initial GWAS set (2 affected cases and 38 controls*), 6 other affected cases and 192 controls.

\begin{tabular}{|c|c|c|c|c|}
\hline c.2363+1 genotype ${ }^{a}$ & Case (n) & Control (n) & Total & \\
\hline $\mathrm{G} / \mathrm{G}$ & 0 & 220 & 220 & \\
\hline $\mathrm{G} / \mathrm{T}$ & 0 & 10 & 10 & \\
\hline $\mathrm{T} / \mathrm{T}$ & 8 & 0 & 8 & P-value $4.4 \times 10^{-15}$ \\
\hline
\end{tabular}

a $\mathbf{T}$ is mutant allele

* NB Data on c.2363+1 genotype is missing for one control dog

1 
Figure 2

Manhattan plot toillustrate results of GWAS analysis

Manhattan plot on two cases and 39 controls; 74,374 SNPs. The X-chromosome is omitted. Analyses were conducted using Fisher's exact test and 100,000 permutations to correct for multiple testing using the $\max (\mathrm{T})$ permutation procedure in PLINK. EMP2 = corrected empirical P-value.

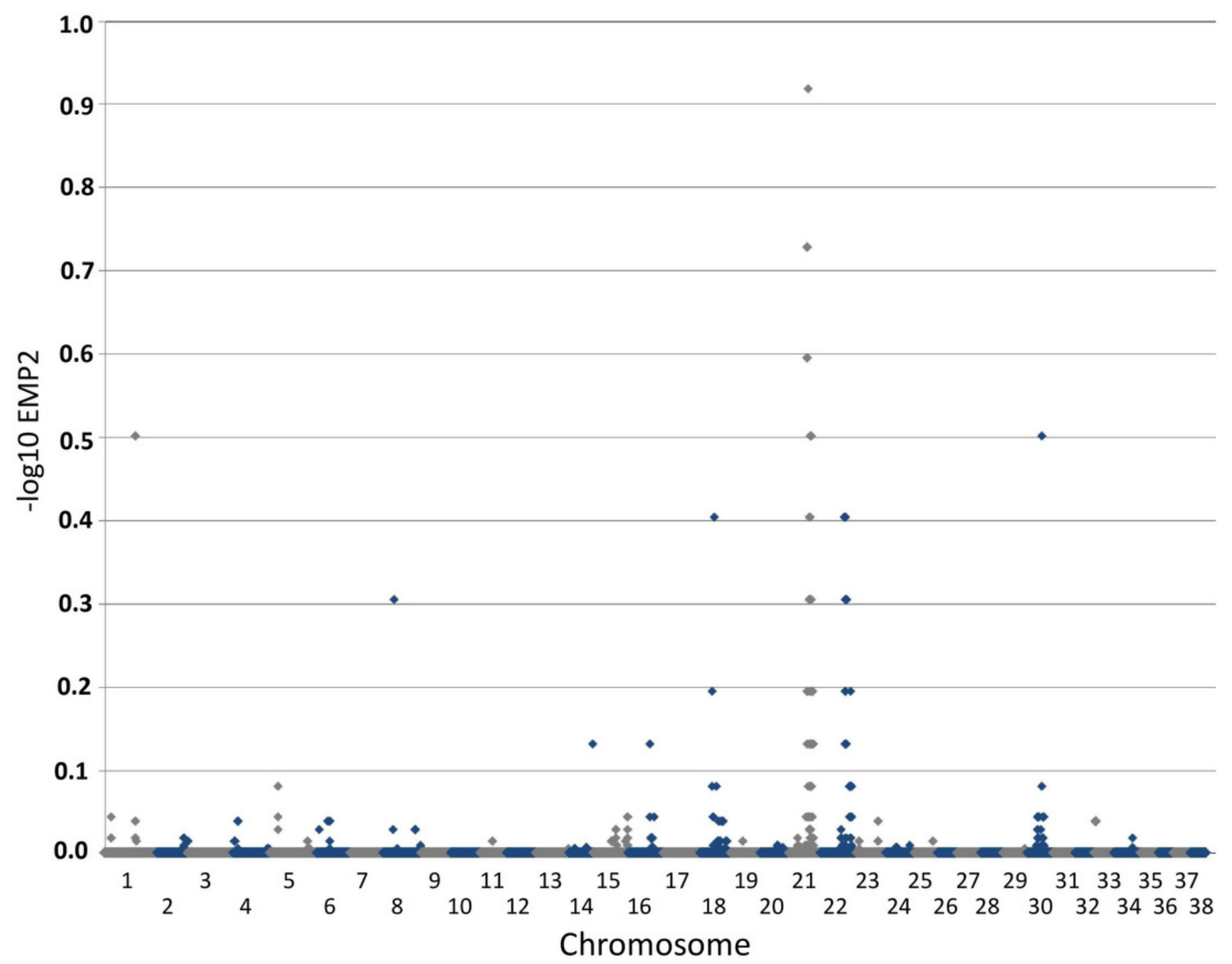


Figure 3

Sanger sequencingelectropherogram traces of the c.2363+1 G>T variant (boxed) in SBF2exon 19.

Trace shows the 3' end of exon 19 and the adjacent intron from PCR products amplified from genomic DNA.

\section{Exon 19}

\section{Intron}

Control

Heterozygote

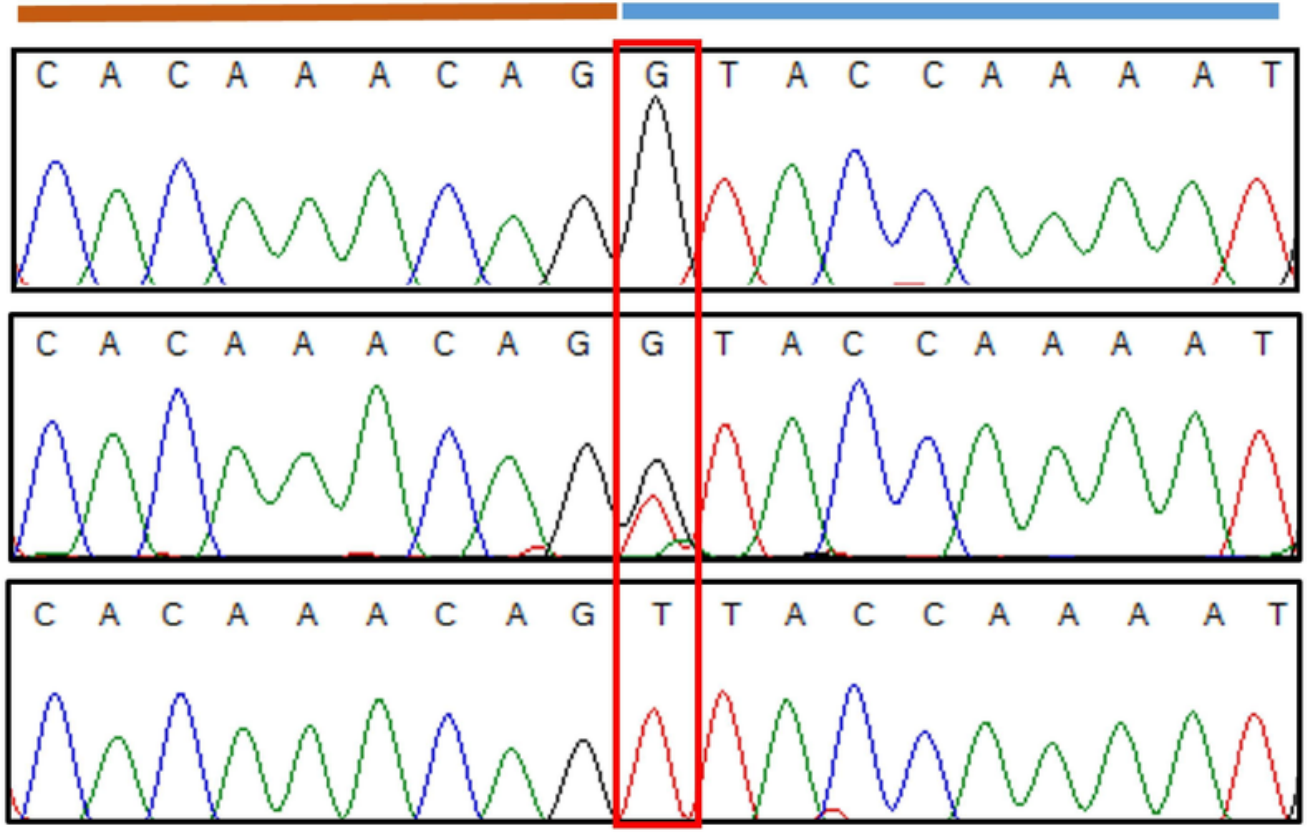


Figure 4

Electropherogram of PCR-amplified CDNA of control and affected dogs.

(A) Electropherogram of PCR-amplified CDNA from a control dog; (B) Electropherogram of PCR-amplified CDNA from an affected dog showing use of a cryptic splice site after disruption of the exon 20 donor site by the c.2363+1 G>T variant. The result is a 40-bp truncation of the transcript. (C) Normal amino acid sequence; (D) The cryptic splice site is positioned at c.2324-c2325 and is predicted to lead to a sequence of 5 aberrant amino acids and premature termination (p.G775Vfs*5).

A

Exon 19 Cryptic splice site

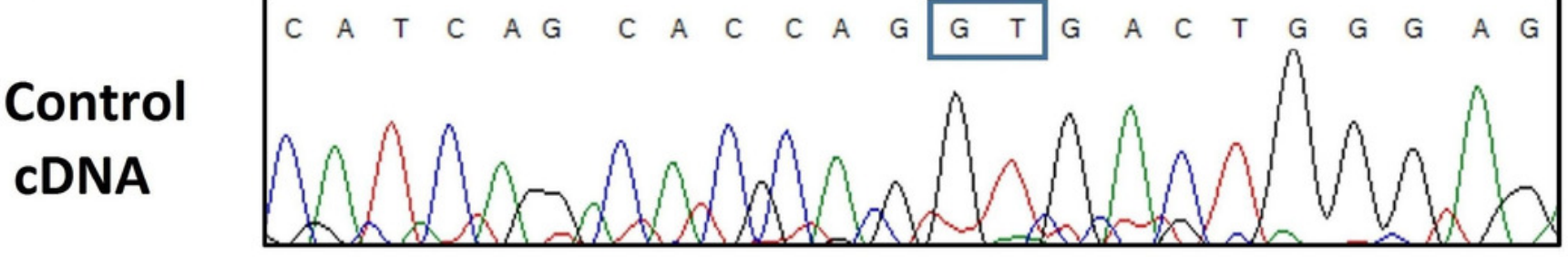

\section{Exon $19 \quad \Omega \quad$ Exon 20}

Case

cDNA

C

Codons: TCA GCA CCA GGT GAC TGG GAG AGT GGA AGC AAC AGC

Amino acids: $S A$ P $G$ D W $E$ S G S $N$

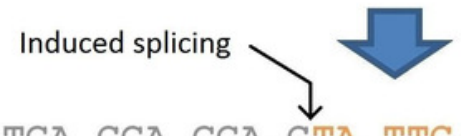

D

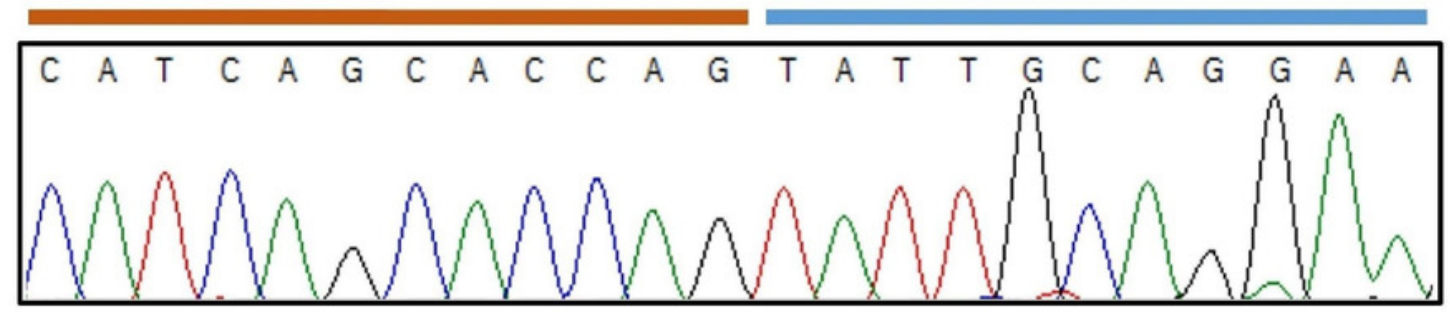

codons: TCA GCA CCA GTA TTG CAG GAA GTG TAG

Amino acids: S A P V $L \quad Q \quad E \quad V$ * 